\title{
Rutebeuf, I fabliaux
}

\section{Matteo Milani}

\section{(2) OpenEdition}

\section{Journals}

\section{Edizione digitale}

URL: http://journals.openedition.org/studifrancesi/9430

DOI: ERREUR PDO dans /localdata/www-bin/Core/Core/Db/Db.class.php L.34 : SQLSTATE[HY000]

[2006] MySQL server has gone away

ISSN: 2421-5856

\section{Editore}

Rosenberg \& Sellier

\section{Edizione cartacea}

Data di pubblicazione: 1 décembre 2007

Paginazione: 627-628

ISSN: 0039-2944

\section{Notizia bibliografica digitale}

Matteo Milani, «Rutebeuf, I fabliauX», Studi Francesi [Online], 153 (LI | III) | 2007, online dal 30 novembre 2015, consultato il 07 janvier 2021. URL: http://journals.openedition.org/studifrancesi/9430 ; DOI: https://doi.org/10.4000/studifrancesi.9430

Questo documento è stato generato automaticamente il 7 janvier 2021.

\section{(c)}

Studi Francesi è distribuita con Licenza Creative Commons Attribuzione - Non commerciale - Non opere derivate 4.0 Internazionale. 


\title{
Rutebeuf, I fabliaux
}

\author{
Matteo Milani
}

\section{NOTIZIA}

RUTEBEUF, I fabliaux, introduzione e traduzione di Alberto LIMENTANI, Roma, Carocci, 2007 («Biblioteca Medievale», 109), pp. 108.

1 L'agile raccolta dei cinque fabliaux di Rutebeuf, poeta multiforme attivo a Parigi tra il 1249 e il 1280, curata da Alberto Limentani e pubblicata per la prima volta a Venezia nel 1976 per la casa editrice Corbo e Fiore, viene oggi opportunamente riproposta, nella sua veste originale, all'interno della collana «Biblioteca Medievale» di Carocci editore.

2 L'introduzione ai testi (pp. 7-27), preceduta da una sintetica nota alla traduzione (p. 6), è suddivisa in cinque sezioni. La prima offre una valutazione complessiva dell'autore e della sua opera, con giudizi assai positivi, peraltro pienamente condivisibili: Rutebeuf, insieme a Jean de Meun, deve considerarsi una delle «due figure di poeti [che] si staccano dalla folta schiera dei verseggiatori operanti entro schemi tradizionali, e rompono bruscamente quegli schemi, prefigurando tempi nuovi» (p. 7), attraverso una variegata serie di scritti che «s'impone come una delle più interessanti della cultura francese medievale» (p. 9). Nella seconda sezione, a seguire le brevi notizie biografiche sul poeta, viene ripercorsa la sua produzione di cinquantacinque componimenti sulla base dei nuclei tematici individuati da Edmond Faral: il conflitto tra la Chiesa, gli Ordini mendicanti e l'Università (I-XVIII), le Crociate (XIX-XXX), la misera condizione del poeta (XXXI-XLI), la materia religiosa (XLII-XLIX), fabliaux, dit e tenzone (L-LV). La celebre definizione «contes à rire en vers» di Joseph Bédier apre la terza sezione, dedicata alle principali teorie sulla definizione del genere: senza trascurare i rilievi mossi da Per Nykrog e le opportune osservazioni proposte da Jean Rychner, il curatore toma infine alla tesi bedieriana del collegamento tra i fabliaux e la nuova borghesia mercantile francese, tesi che a suo giudizio «resta, tutto sommato, la più convincente, anche se tollera eccezioni e abbisogna di sfumature» (p. 14). La quarta sezione, nucleo della parte introduttiva, giustifica la scelta di includere nel piccolo corpus favolistico i 
cinque componimenti pubblicati, di cui vengono sintetizzati motivi e aspetti formali, sempre con uno sguardo attento alla parallela tradizione del genere e alla restante produzione di Rutebeuf: «È questo moralismo, questo credersi perpetuamente in dovere di giudicare e rimbrottare, ciò che connette i fabliaux alla restante opera del poeta, ne crea l'ambiguità di fronte a taluni modelli, ma segna anche l'autonomia, l'originalità della posizione che Rutebeuf viene a occupare» (p. 26). A chiudere, nella quinta sezione, la citazione della celebre strofa indirizzata ai ribaldi di Place de la Grève apre le porte a una nuova chiave di lettura, che, in prospettiva storica, riconosce al poeta, più che il titolo «di primo 'lirico moderno', [attribuito] da parte dei letterati del nostro tempo» (p. 26), «il ruolo di 'profeta' di Villon [...], nella sua varia e non sempre coordinata attività poetica così come in alcuni aspetti della sua avventura umana e del suo inerire in una condizione di umile, se non di diseredato» (p. 27).

3 Seguono i cinque fabliaux: De la damme qui fisi trois tours entour le moustier Da donna che fece tre giri intorno alla chiesa (pp. 29-41), Ci encoumence de Charlot le Juif qui chia en la pel dou lievre Charlot e la pelle della lepre (pp. 43-53), De frere Denise Fra Dionigi (pp. 55-75), C'est le testament de l'asne $\sim$ Il testamento dell'asino (pp. 77-89) e Le pet au villain Il peto del villano (pp. 91-97), secondo il testo dell'edizione Faral-Bastin, salvo piccoli ritocchi, con traduzione italiana a fronte.

4 Per ciascuno di essi il curatore propone brevi note (pp. 99-102), a carattere precipuamente esplicativo, con rimandi ai versi francesi, precedute per il secondo, il terzo e il quarto fabliau da un rapidissimo cappello introduttivo.

5 La bibliografia (pp. 103-104), davvero essenziale e ferma ai contributi ante 1976, è suddivisa in «Edizioni» e «Studi», che comprendono a loro volta «Opere d'insieme sui fabliaux, con pagine dedicate a quelli di Rutebeuf», «Opere d'insieme su Rutebeuf» e «Sui fabliaux di Rutebeuf».

6 Manca, è vero, un opportuno aggiornamento proprio in materia bibliografica, ma l'interesse per l'edizione curata da Limentani resta intatto a trent'anni di distanza dalla sua prima apparizione: suo merito principale la chiarezza, esercitata con eguale acume nella traduzione dei testi editi e nella stesura delle pagine introduttive.

7 Queste ultime, sulle quali più a lungo ci siamo soffermati, riescono a tratteggiare un quadro nitido del poeta e del genere favolistico, offrendo al lettore numerosi e sempre interessanti spunti di approfondimento.

8 La breve raccolta si propone dunque quale strumento sintetico e pregnante per un primo approccio alla materia e come valido supporto didattico in ambito universitario, secondo la tradizionale impostazione della collana della quale da oggi entra a far parte. 